\title{
THE ATHEROSCLEROSIS-INFLAMMATION RELATIONSHIP - A PATHOPHYSIOLOGICAL APPROACH
}

\author{
DENISA-MĂDĂLINA ZĂLAR ${ }^{1}$, CRISTINA POP $^{1 *}$, ELENA BUZDUGAN $^{2}$, DOINA TODEA $^{3}$, \\ CRISTINA IONELA MOGOȘAN ${ }^{1}$ \\ ${ }^{1}$ Department of Pharmacology, Physiology and Pathophysiology, Faculty of Pharmacy, "Iuliu Hațieganu” University of \\ Medicine and Pharmacy, Cluj-Napoca, Romania \\ ${ }^{2}$ Department of Cardiology, Vth Medical Clinic, Faculty of Medicine, "Iuliu Hațieganu” University of Medicine and \\ Pharmacy, Cluj-Napoca, Romania \\ ${ }^{3}$ Department of Pneumology, Faculty of Medicine, “Iuliu Hațieganu” University of Medicine and Pharmacy, Cluj-Napoca, \\ Romania
}

*corresponding author: pop.cristina@umfcluj.ro

Manuscript received: March 2019

\begin{abstract}
Atherosclerosis is the predominant pathological substrate of cardiovascular diseases and through its major complications (ischemic heart disease and stroke) represents the main cause of mortality and morbidity in the developed countries. It is a chronic inflammatory disease derived from the aggregation of lipids and different types of immune cells along with macrophages, $\mathrm{B}$ and $\mathrm{T}$ cells in the arterial wall. Recent studies revealed that during atherogenesis, the interaction between lipids and immune cells represents the driving force in the chronic inflammation of the arterial wall. The present paper compiles the pathophysiology of atherosclerotic disease as it describes the involvement of the immune system, analysing the important roles of endothelial dysfunction, macrophages, LDL oxidation and smooth muscle cell migration and proliferation.
\end{abstract}

\section{Rezumat}

Ateroscleroza este principalul substrat patologic al bolilor cardiovasculare și prin complicațiile sale majore (boala cardiacă ischemică și accidentul vascular cerebral) reprezintă principala cauză de mortalitate și morbiditate în țările dezvoltate. Este o afecțiune inflamatorie cronică care rezultă din acumularea de lipide și mai multe tipuri de celule implicate în imunitate, incluzând macrofage, limfocite B şi T la nivelul peretelui arterial. Studiile recente au arătat că, în timpul aterogenezei, interacțiunea dintre lipide și celulele imune reprezintă o forță motrice a inflamației cronice a peretelui arterial. Această lucrare analizează fiziopatologia bolii aterosclerotice, din perspectiva contribuției sistemului imunitar, punând în evidență rolul crucial al disfuncției endoteliale, macrofagelor, oxidarii LDL, migrării și proliferării celulelor musculare netede.

Keywords: atherosclerosis, inflammation, endothelial dysfunction

\section{Introduction}

Cardiovascular disease (CVD) represents the most prevalent cause of death worldwide, leading to 17.3 million deaths annually, accounting for $31.5 \%$ of all deaths [35]. More than 4 million cardiovascular deaths occur in Europe annually, with higher rates among women (2.1 million) than among men (1.8 million). Ischemic heart disease (IHD) and stroke are the main causes of mortality in Europe, responsible for 1.267.000 deaths (28\% of all deaths) among men and 1,460,000 deaths (33\%) among women, each year [47]. In Romania the death rates pe year from all CVD are around 149.060 (58.50\%), IHD and stroke being responsible for 45.041 (30.21\%) deaths among men and 50.630 (33.96\%) among women [51].

Studies have shown that over $19 \%$ of adults in Romania have 3 or more vascular risk factors including dyslipidaemia [7]. The prevalence of dyslipidaemia among the adult population in our country is over $46 \%$ [10].
Atherosclerosis is one of the leading risk factors underlying CVD, and the clinical manifestations are coronary artery disease (CAD), stroke, transient ischemic attack (TIA), cerebral aneurysm, vascular malformation, stenosis and occlusion of non-cerebral and noncoronary arteries and aortic aneurysm. The vascular complications of atherosclerosis are acute myocardial infarction (IM), stroke and ischemic limbs and viscera [38, 39].

It is considered that atherosclerosis is a lifelong inflammatory condition influencing the large and medium-sized arteries defined by a complex interaction between endothelial dysfunction, lipid deposits, innate and adaptive immune system reaction, smooth muscle cell (SMC) migration and proliferation and extracellular matrix reshaping, that can lead to the development of an intimal plaque $[1,33]$. The atherosclerotic process is triggered by endothelial dysfunction which allows lipoproteins to enter and accumulate in the subendothelial space where they go through chemical and 
physical changes making them more pro-inflammatory and activating endothelial cells (ECs) [9, 32, 55]. Activated ECs induce the expression of adhesion molecules which mediate the rolling and firm arrest of monocytes and $\mathrm{T}$ cells. Once entered in the intima, monocytes become macrophages, under the action of two growth factors granulocyte-macrophage colonystimulating factor (GM-CSF) and macrophage-colonystimulating factor (MCS-F), that upregulate toll-like receptors (TLRs), and with the help of scavenger receptors (SRs) engulf oxidized LDL (oxLDL), resulting in lipid aggregation and foam cell development [15, 25]. The onset is insidious, atherosclerosis can appear early in life, with a long asymptomatic phase that can progress under the influence of cardiovascular risk factors. Different classifications of cardiovascular risk factors are in use. The traditional or conventional CV risk factors (hypertension, hypercholesterolemia, smoking, diabetes mellitus) were the first described, to which new or non-traditional risk factors (abdominal obesity, microalbuminuria, anaemia, metabolic syndrome) were added [19].

In this review, we focus on current opinions regarding the pathological mechanisms of the major factors involved in atherosclerosis, including biomechanical factors, endothelial dysfunction, LDL oxidation, with a major accent on immune system activation and SMC migration and proliferation.

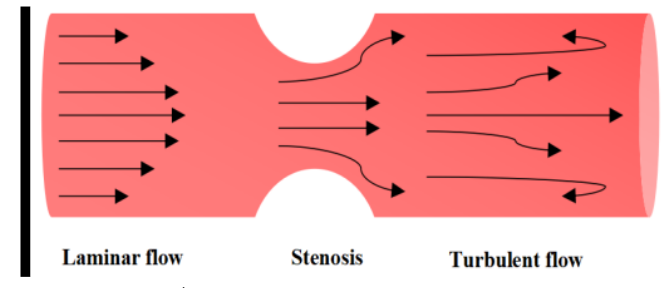

A

\section{The role of biomechanical factors in atherosclerosis}

Blood, immune cells, oxygen, paracrine hormones, are delivered in every cardiac cycle through arteries and arterioles under pulsatile pressure to peripheral organs. Complex biomechanical forces are generated on the vessel wall as the result of the interactions between pulsatile blood flow and arterial geometries.

The arterial wall, endothelial cells, and atherosclerotic tissue are deformed as a result of these complex mechanical forces. These forces act in circumferential, radial and axial directions and induce stress into the vessel wall $[8,45]$. Wall (or endothelial) shear stress (WSS) and plaque structural stress (PSS), are the two most important biomechanical factors that have been hypothesized to be implicated in the induction and evolution of atherosclerosis.

WSS represents the parallel force vector component applied by the blood flow onto the vascular wall, stretching the artery in the longitudinal direction. Its tension increases proportionally with blood velocity and viscosity, so with increased blood flow, WSS also intensifies, decreasing the vascular tone of SMC and therefore produces vasodilation. Shear stress is the stress located either into the normal arterial wall (WSS) or within the atherosclerotic plaque (PSS), as a result of the vessel extension and stretch induced by arterial pressure [2].

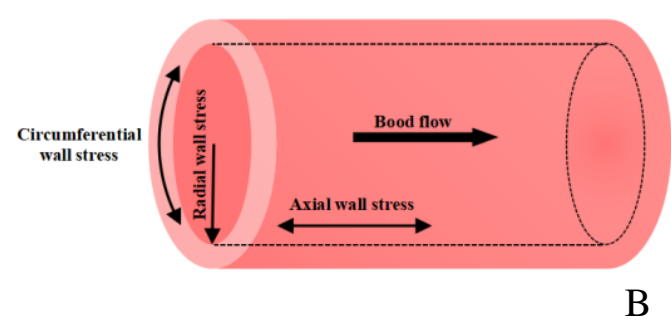

Figure 1.

The influence of stenosis and hemodynamic forces on the blood flow

(A). Atherosclerotic plaque causes narrowing of the vascular wall resulting in blood flow changes, making the transition from laminar flow to turbulent flow; (B). Hemodynamic forces acting on the blood vessel wall are: the circumferential wall stress; axial wall stress and radial wall stress

The atherosclerotic plaque causes narrowing of the arterial lumen resulting in increased blood velocity and therefore increased shear stress within the stenotic region. Additionally, the endothelium next to the narrowed area is exposed to WSS.

Short-term changes of shear stress lead to functional changes in the arteries. Prolonged intensified hemodynamic stress leads to the initiation of endothelial lesions. As a consequence of the increase in shear stress, activated ECs secrete prostacyclin and nitric oxide (NO), which promote vasodilation $[6,17]$.

\section{Endothelial dysfunction in atherosclerosis}

Vascular homeostasis is mainly regulated by endothelial cells and one of its most important functions is to maintain the vasoconstriction-vasodilation balance, thrombogenesis and fibrinolysis, stimulation and prevention of SMC proliferation and transfer into the intimal layer $[21,22]$. When this is disrupted, a disturbance of the endothelial function occurs, inducing an impairment in the arterial wall.

Healthy endothelium undergoes vascular repair and remodelling, senses and mechanotransduces hemodynamic forces. NO initially identified as an endotheliumderived relaxing factor (EDRF), is the main vasodilatory substance released by ECs. Prostacyclin and bradykinin are generated by cyclooxygenase (COX) in the endothelium and also exhibit vasodilatory properties [36, 37]. Prostacyclin has significant antiplatelet effects and thus limits platelet aggregation [21, 22]. Bradykinin 
induces the deliverance of NO, prostacyclin, and endothelium-derived hyperpolarizing factor, that is an important vasodilator in the microcirculation, promoting the inhibition of the platelet aggregation process [36, 37]. Bradykinin is essential for fibrinolysis by stimulating tissue plasminogen activator (t-PA).

Endothelin (the most effective endogenous vasoconstrictor described to date) and angiotensin II are two vasoconstricting substances, also produced by ECs that contribute to plaque development by stimulating the proliferation of smooth muscle cells [37, 54].

The imbalances between vasoconstriction and vasodilation in response to endothelial dysfunction, lead to maladaptive responses that stimulate or increase atherosclerosis; these involve increased endothelial permeability, platelet aggregation, leukocyte adhesion and cytokines release [54]. One of the first signs of atherosclerosis may be a reduced release or activity of NO, manifested as disturbed vasodilation. NO is generated via an oxidation reaction of L-arginine in the presence of endothelial NO synthase (eNOS), produce L-citrulline and stoichiometric amounts of NO. Tetrahydrobiopterin (THB4) and nicotinamide adenine dinucleotide phosphate (NADPH) are 2 cofactors involved in NO production [30].
Once generated, NO diffuses into SMC, activating intracellular guanylate cyclase, increases cyclic guanosine monophosphate (cGMP) levels, decreasing intracellular calcium levels and promoting vasodilation [24].

\section{The role of oxLDL}

High amounts of circulating lipids have an important role in the progression of atherosclerosis. Apolipoprotein $\mathrm{B}(\mathrm{ApoB})$ is the principal structural apolipoprotein in low-density lipoproteins (LDL), vital for its construction and growth. ApoB exists in 2 forms in the human body: ApoB100 which is present in the liver and therefore it appears on the liver-derived lipoproteins very-low-density-lipoprotein (VLDL), intermediate density lipoprotein (IDL) and LDL [11]. Another form is ApoB48 that is present in the intestine and it is expressed on chylomicrons. During atherosclerotic lesion development, LDL represents the main source of lipid accumulation within the arterial wall. In vitro studies have shown that intracellular cholesterol accumulation is induced by atherogenic modified LDL and not by native LDL. Modified LDL is internalized especially through unregulated phagocytosis following a different metabolic pathway compared to native LDL [49].

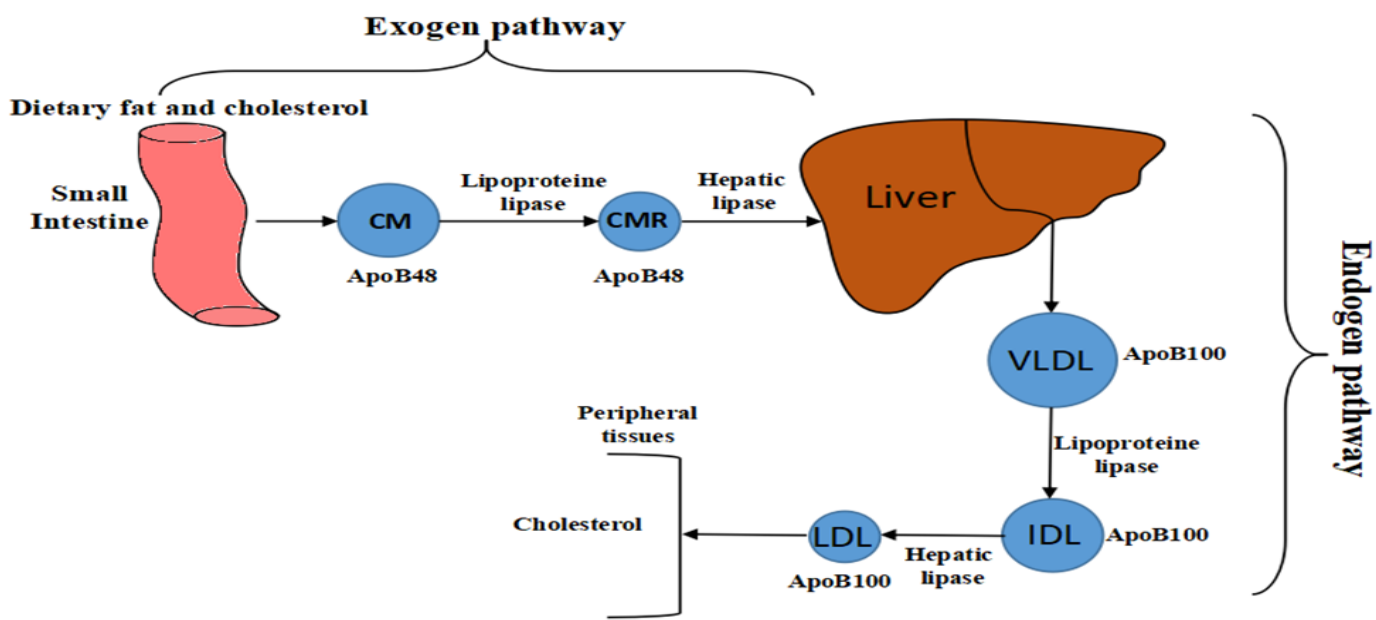

Figure 2.

Lipid metabolism. CM, chylomicrons; CMR, chylomicrons remnant; Apo B48, apolipoprotein B48; VLVL, very low-density lipoprotein; IDL, intermediate density lipoprotein; LDL, low-density lipoprotein; Only the predominant lipids are shown

Through transcytosis, lipoproteins with a diameter smaller than $70 \mathrm{~nm}$ have the capacity to transverse the endothelium, where ApoB containing lipoproteins bind to proteoglycans (such as heparan, chondroitin, dermatan and keratin) through electrostatic binding $[14,31,48]$. Subsequently binding to proteoglycans, LDL undergoes a physical change concerning ApoB100 and lipid composition $[4,23,28]$. In patients with atherosclerosis, plasma analysis revealed different types of LDL alterations including the acquisition of negative electric charges, glycation, desialylation, and acetylation [34]. Proteoglycan-bound LDL thus becomes more prone to oxidation, generating inflammation and ECs activation. Once traped at the subendothelial level, LDL oxidation occurs in the presence of reactive oxygen and nitrogen species released by vascular cells $[5,42$,$] .$

\section{Immune system activation in atherosclerosis}

It was thought that atherosclerotic plaques develop passively by deposition of lipids in the endothelium. However, it was shown that atherosclerosis is the result of chronic inflammation within the arterial wall caused 
by the accumulation of LDL and leukocytes. The pathophysiology of atherosclerosis is complex and it is believed to start with lipid accumulation at the level of the intima, tissue macrophage activation and production of cytokines such as tumour necrosis factor- $\alpha$ (TNF- $\alpha$ ) and interleukin-1 $\beta$ (IL-1 $\beta)$. Cytokines stimulate endothelial production of adhesion molecules such as E- and P-selectins, vascular cell adhesion molecule 1 (VCAM-1) and intercellular adhesion molecule 1 (ICAM-1) [20]. These molecules facilitate endothelial adhesion and transmigration into the intima of various leukocytes (monocytes, T and B-cells, neutrophils). Monocytes present several membrane structures capable of interacting with adhesion molecules such as P-selectin glycoprotein ligand-1 (PSGL-1) or monocyte-expressed very late antigen4 (VLA-4) [43].

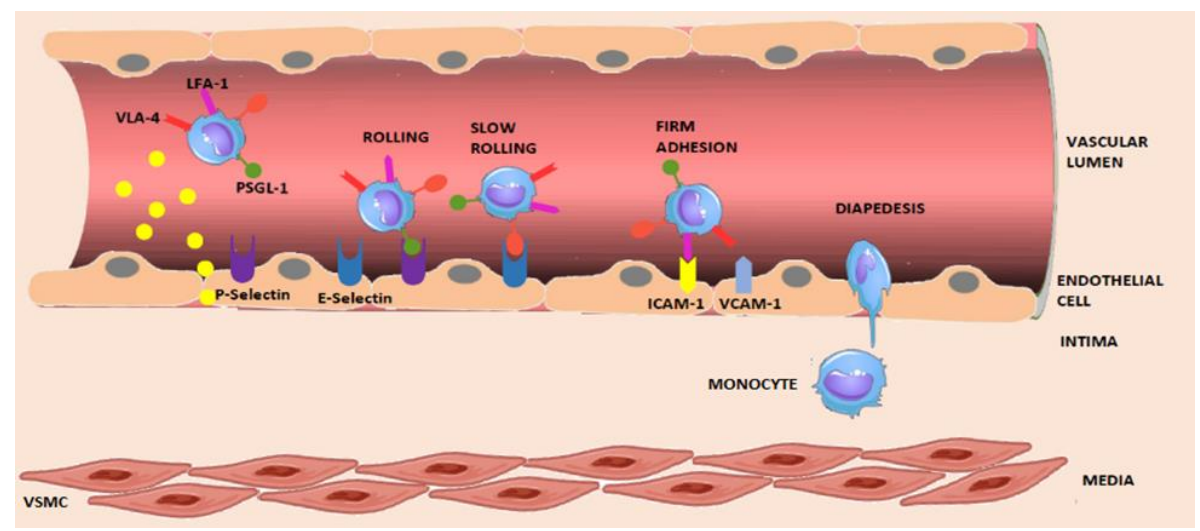

Figure 3.

Monocytes endothelial adhesion and transmigration into the intima

Monocytes are activated to macrophages by different growth factors such as monocyte-colony stimulating factor (M-CSF), as well as cytokines such as TNF- $\alpha$, IL-1 $\beta$, interleukin-4 (IL-4), interleukin-8 (IL-8), interleukin-13 (IL-13) and interferon- $\gamma($ IFN- $\gamma)$. Atherosclerosis involves the transformation of monocytes into macrophages. M-CSF-knockout mice display resistance to atherosclerosis development [39]. Subsequently, IFN- $\gamma$ triggers macrophages to produce neopterin, a potentially useful atherosclerosis and inflammation marker [39].

Recent studies have shown that cytokines may influence macrophage activation [29]. In this respect, two major types of macrophages have been identified: M1 and M2. M1 secretes pro-inflammatory cytokines such as IL-12, IL-6 and TNF- $\alpha$ and may enhance plaque vulnerability. M2 produces anti-inflammatory cytokines such as IL-10 and TGF- $\beta$ and increases plaque stability. M1 differentiation is stimulated by IL-1 $\beta$ and IFN- $\gamma$ secreted by T-helper cells 1 (Th1), whereas M2 differentiation is stimulated by IL-4 and IL-13 secreted by Th2 [29].

Reactive oxygen species (ROS) are formed under various conditions such as myeloperoxidases release by neutrophils or IFN- $\gamma$ release by macrophages and other cells. ROS oxidize LDL molecules at different degrees. In the first stage, LDL oxidation produces a minimally oxidized LDL (mmLDL), with proinflammatory activity. Further oxidation of mmLDL leads to moderately oxidized LDL (moLDL) formation, and finally, even further oxidation leads to strongly oxidized LDL (oxLDL). Macrophages express scavenger receptors: SR-A1, Toll-like receptor 4 (TLR-4), lectintype oxidized LDL receptor 1 (LOX-1) or CD36 and CD68 that can distinguish between mmLDL, moLDL and oxLDL [44]. TLR-4 recognize mmLDL, whereas LOX1, SR-A1 and CD36 identify moLDL and oxLDL [44]. Upon expression of scavenger receptors, macrophages uptake and phagocyte oxLDL, thus becoming foam cells.

Dendritic cells (DCs) are important components of the immune system, which have recently been found to be involved in atherosclerosis. There are four major types of DCs: conventional, plasmacytoid, monocytederived and Langerhans cells. Granulocyte macrophage colony stimulating factor (GM-CSF) or TLR-4 ligands influence the transformation of monocytes into monocyte-derived DCs. Monocyte-derived DCs generate proinflammatory cytokines (TNF- $\alpha$, IL-6 and IL-12), but also atheroprotective cytokines such as IL-10. DCs express scavenger receptors (LOX-1, CD36 and CD205) which facilitate oxLDL uptake and the activation of intracellular pathways leading to enhanced proinflammatory cytokines production [39].

Atherosclerotic lesions present $\mathrm{T}$ cells in a lesser extent compared to macrophages. Activation of $\mathrm{T}$ cells is the result of the interactions with antigens, leading to pro-inflammatory cytokines production and worsening of atherosclerosis. Most T cells involved in atherosclerosis are Th1. They secrete IFN- $\gamma$ which activates macrophages and recruits vascular smooth muscle cells to inhibit collagen synthesis, thus destabilizing the plaque. IFN- $\gamma$ is thought to be an interesting therapeutic target in atherosclerosis. Th2 cells have 
controversial roles in atherosclerosis. They decrease IFN- $\gamma$ production but also stimulate antibody production by B cells, and secrete cytokines like IL-4, IL-5, IL-9 and IL-13. Regulatory T cells (Tregs) are important inflammation suppressors by producing IL-10 and by regulating other adaptive immune responses. Other $\mathrm{T}$ cells involved in pro-atherosclerogenesis are: Th17, CD4 + T cells and CD8 + T cells, although Th17 has also displayed atheroprotective effects [27].

B cells can be identified in atherosclerotic plaques in a lesser extent compared to T cells. Their roles in atherosclerosis are controversial. The use of an antibody against CD20 has resulted in the inhibition of atherosclerosis progression. Also, studies show that anti-oxLDL IgM, have atheroprotective effects, whereas oxLDL-specific IgG have atherosclerotic effects [39]. In conclusion, atherosclerosis development and progression involve many components of both innate and adaptive immune systems. Currently, there is an increasing interest in the study of the relationship immune system-atherosclerosis for diagnostic and prognostic purposes, but also for therapeutic targeting in atherosclerosis $[13,16,52]$.

\section{Smooth muscle cells migration and proliferation}

The main support for the vessel wall structure is provided by smooth muscle cells (SMC), by vascular tone regulation and thus maintenance of blood pressure and perfusion. SMC present increased plasticity in order to accomplish various functions: extracellular matrix synthesis, contraction and proliferation [46].

SMC can present with two phenotypes: the contractile phenotype, which mediates vasodilatation and vasoconstriction, and the proliferating phenotype [12]. As a reaction to injury, the contractile phenotype will transform into the proliferative phenotype.

Morphological and functional properties of SMC may change under the influence of growth factors, inflammation mediators and mitogens. SMC may be unable to contract, but gain abilities such as migration, proliferation and accumulation in the intima [40]. In response to injury, macrophages secrete various growth factors such as: platelet-derived growth factor (PDGF), epidermal growth factor (EGF), insulin growth factor (IGF), fibroblast growth factor (FGF), vascular endothelial growth factor (VEGF), and transformer growth factor (TGF) and also angiotensin II (AngII).

The PDGF induces the migration of smooth muscle cells from media to intima. IL-1, thrombin and TNF- $\alpha$ stimulate PDGF activity [26]. Once the SMC migrate, factors such as FGF, heparin affinity growth factor (HB-EGF) and PDGF stimulate cell growth and division [50]. Also, VEGF contributes to SMC proliferation [26]. SMC produce the elements that form the extracellular matrix. This matrix consists of type I collagen and type III collagen, elastin and proteoglycans. Extracellular matrix formation is controlled by matrix metalloproteinases (MMPs), which due to their enzymatic activity destroy various macromolecules within the matrix [3].

SMC can lead to vascular remodelling and intimal vascular lesions if they fail to shift to the contractile phenotype [18].

The proliferating phenotype of SMC diminishes contractile protein expression and increases the expression of extracellular matrix proteins, thus controlling vascular remodelling [41]. SMC accumulation in the intima is an important process in advanced atherosclerotic lesions. This accumulation is followed by slow proliferation, with various intensities of cell division due to intermittent rupture in the atheromatous plaque. Cell proliferation is inhibited by various cytokines (TGF- $\alpha$, IFN- $\gamma$ ) [53]. Additionally, SMC apoptosis inhibits proliferation, which explains the increased fibrous content and reduced cellular architecture in the mature atheromatous plaque.

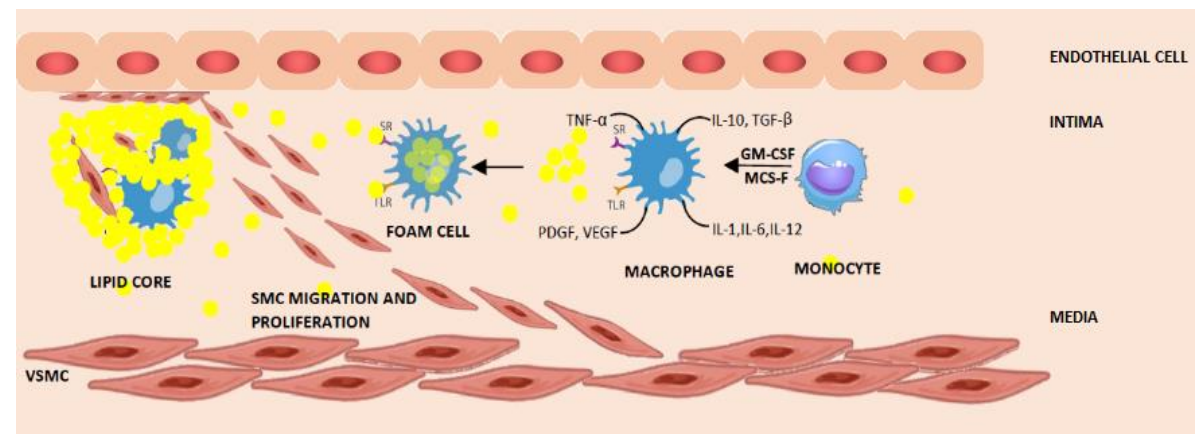

Figure 4.

Smooth muscle cell migration and proliferation. Once entered in the subendothelial space, monocytes differentiate into macrophage, under the influence of two growth factors: GM-CSF and M-CSF. Macrophages, through scavenger receptors (SR) and Toll-like receptors (TLR) engulf the oxLDL, releasing pro-inflammatory cytokines (TNF- $\alpha$, IL-1, IL-6, IL-12) and become foam cells. Activated macrophages also release plateletderived growth factor (PDGF) and vascular endothelial growth factor (VEGF), two factors that induce the migration of smooth muscle cells from the media to the intima 
It must be mentioned that SMC that migrate to the intima are morphologically different from native SMC from media. Under the action of external stimuli, SMC change morphologically by reducing the number of monofilaments and increasing organelles involved in protein synthesis (the Golgi apparatus and the endoplasmic reticulum) [12]. Thus, SMC found in the atheromatous plaque are histologically immature but have increased secretory activity.

Similar to macrophages, SMC can accumulate lipoproteins at the cytoplasmic level, transforming into foam cells.

\section{Conclusions}

Atherosclerosis is a multifactorial disease whose pathogenesis is not fully understood, but inflammation and its complex cellular processes play an important role in the initiation and progression of atherosclerotic lesions, therefore, administration of compounds with anti-inflammatory potential could be a valuable therapeutic solution.

Immuno-inflammatory mechanisms are directly involved in the initiation and progression of cardiovascular diseases from the incipient asymptomatic stage of vascular injury to clinical manifestations of dysfunction and vascular remodelling.

Given the multifactorial nature of this process, additional studies are essential for improving our knowledge in this field, from experimental models to human tissue assessment, systemic biomarkers, epidemiological and clinical observations.

\section{References}

1. Back M, Weber C, Lutgens E, Regulation of atherosclerotic plaque inflammation. J Intern Med., 2015; 278: 462-482.

2. Brown AJ, Teng Z, Evans PC, Gillard JH, Samady $\mathrm{H}$, Bennett MR, Role of biomechanical forces in the natural history of coronary atherosclerosis. Nat Rev Cardiol., 2016; 13(4): 210-220.

3. Buckley ML, Ramji DP, The influence of dysfunctional signaling and lipid homeostasis in mediating the inflammatory responses during atherosclerosis. Biochim Biophys Acta., 2015; 1852: 1498-1510.

4. Camejo G, Hurt E, Wiklund O, Rosengren B, Modifications of low-density lipoprotein induced by arterial proteoglycans and chondroitin-6-sulfate. Biochim Biophys Acta., 1991; 1096: 253-261.

5. Camejo G, The interaction of lipids and lipoproteins with the intercellular matrix of arterial tissue: its possible role in atherogenesis. Adv Lipid Res., 1982; 19: $1-53$

6. Chouinard-Pelletier G, Jahnsen ED, Jones EA, Increased shear stress inhibits angiogenesis in veins and not arteries during vascular development. Angiogenesis, 2013; 16: 71-83.

7. Cinteza M, Pana B, Cochino E, Florescu M, Margulescu A, Prevalence and control of cardiovascular risk factors in Romania: CARDIO-ZONE national transversal study. Maedica A Journal of Clin Med., 2007; 2(4): 277-288.

8. Davies PF, Hemodynamic shear stress and the endothelium in cardiovascular pathophysiology. Nat Clin Pr Cardiovasc Med., 2009; 6: 16-26.

9. Deng W, Deng Y, Deng J, Wang DX, Zhang T, Losartan attenuated lipopolysaccharide-induced lung injury by suppression of lectin-like oxidized lowdensity lipoprotein receptor-1. Int J Clin Exp Pathol., 2015; 8: 15670-15676.

10. Dorobantu M, Badila E. Studiul SEPHAR. Rev Rom Med Interna, 2006; 4: 9-18, (available in Romanian).

11. Dunn S, Vohra RS, Murphy JE, Homer-Vanniasinkam S, Walker JH, Ponnambalam S, The lectin-like oxidized low-density-lipoprotein receptor: a pro-inflammatory factor in vascular disease. Biochem J., 2008; 409(2): 349-355.

12. Enis DR, Shepherd BR, Wang Y, Qasim A, Shanahan CM, Induction, differentiation, and remodeling of blood vessels after transplantation of Bcl-2transduced endothelial cells. Proc Natl Acad Sci USA, 2005; 102: 425-430.

13. Gister A, Hermansson A, Strodthoff D, Klement ML, Hedin U, Fredrikson G, Vaccination against T-cell epitopes of native ApoB 100 reduces vascular inflammation and disease in a humanized mouse model of atherosclerosis. J Intern Med., 2017; 281: 383-397.

14. Glass CK, Witztum JL, Atherosclerosis, the road ahead. Cell., 2001; 104: 503-516.

15. Hansson GK, Robertson AK, Soderberg-Naucler C, Inflammation and atherosclerosis. Аnпи Rev Pathol., 2006; 1: 297-329.

16. Herghelegiu AM, Prada GI, Nacu RM, Kozma A, Alexa ID, Statins use and risk of sarcopenia in community dwelling older adults. Farmacia, 2018; 66(4): 702-707.

17. Hoefer IE, Adel B, Daemen MJ, Biomechanical factors as triggers of vascular growth. Cardiovasc Res., 2013; 99: 276-283.

18. House SJ, Potier M, Bisaillon J, Singer HA, Trebak $\mathrm{M}$, The non-excitable smooth muscle: calcium signaling and phenotypic switching during vascular disease. Pflugers Arch., 2008; 456: 769-785.

19. Hovland A, Jonasson L, Garred P, Yndestad A, Aukrust A, Knut T, The complement system and toll-like receptors as integrated players in the pathophysiology of atherosclerosis. Atherosclerosis, 2015; 241: 480-494.

20. Ilhan F, Kalkanli ST, Atherosclerosis and the role of immune cells. World J Clin Cases, 2015; 3(4): 345-352.

21. Kataoka H, Kume N, Miyamoto S, Minami M, Moriwaki H, Expression of lectin-like oxidized lowdensity lipoprotein receptor-1 in human atherosclerotic lesions. Circulation, 1999; 99(24): 3110-3117.

22. Kinlay S, Libby P, Ganz P, Endothelial function and coronary artery disease. Curr Opin Lipidol., 2001; 12: 383-389.

23. Kugiyama K, Ota Y, Takazoe K, Moriyama Y, Miyao Y, Sakamoto T, Circulating levels of secretory type II phospholipase $\mathrm{A}(2)$ predict coronary events in patients with coronary artery disease. Circulation, 1999; 100: 1280-1284. 
24. Landmesser U, Honig B, Endothelial function. A critical determinant in atherosclerosis. Circulation, 2004; 109: 27-33.

25. Libby P, Inflammation in atherosclerosis. Arterioscler Thromb Vasc Biol., 2012; 32(9): 2045-2051.

26. Lim S, Park S, Role of vascular smooth muscle cell in the inflammation of atherosclerosis. BMB Rep., 2014; 47: 1-7.

27. Mallat Z, Taleb S, Ait-Oufella H, Tedgui A, The role of adaptive $T$ cell immunity in atherosclerosis. J Lipid Res., 2009; 50: S364-S369.

28. Mateu L, Avila EM, Camejo G, Leon V, Liscano N, The structural stability of low-density lipoprotein. A kinetic X-ray scattering study of its interaction with arterial proteoglycans. Biochim Biophys Acta., 1984; 795: 525-534.

29. McLaren JE, Michael DR, Ashlin TG, Ramji DP. Cytokines, macrophage lipid metabolism and foam cells: Implications for cardiovascular disease therapy. Prog Lipid Res., 2011; 50: 331-347.

30. Mehta JL, Chen J, Hermonat PL, Romeo F, Novelli G, Lectin-like, oxidized low-density lipoprotein receptor1 (LOX-1): A critical player in the development of atherosclerosis and related disorders. Cardiovasc Res., 2006; 69(1): 36-45.

31. Mestas J, Ley K, Monocyte-endothelial cell interactions in the development of atherosclerosis. Trends Cardiovasc Med., 2008; 18: 228-232.

32. Milstone D, Ilyama S, Chen M, O'Donnell P, Davis V, Plutzky J, Differential role of an NF-B transcriptional response element in endothelial versus intimal cell VCAM-1 expression. Circ Res., 2015; 117:166-177.

33. Mogoşan C, Voştinaru O, Pârvu AE, Pop C, Zaharia $\mathrm{V}$, An evaluation of the anti-inflammatory potential of some polyheterocyclic compounds with thiazole rings in acute inflammation models. Part I. Vascular Response. Farmacia, 2013; 61(2): 323-329.

34. Moore KJ, Freeman MW, Scavenger receptors in atherosclerosis: beyond lipid uptake. Arterioscler Vasc Biol., 2006; 26(8): 1702-1711.

35. Naghavi M, Wang H, Lozano R, Davis A, Liang X, Global, regional, and national age-sex specific all-cause and cause-specific mortality for 240 causes of death, 1990-2013: a systematic analysis for the Global Burden of Disease Study 2013. Lancet, 2015; 385: 117-171.

36. Pirillo A, Reduzzi A, Ferri N, Kuhn H, Corsini A, Catapano L, Upregulation of lectin-like oxidized low-density lipoprotein receptor-1 (LOX-1) by 15 lipoxygenase-modified LDL in endothelial cells. Atherosclerosis, 2011; 214(2): 331-337.

37. Pirillo A, Uboldi P, Ferri N, Corsini A, Kuhn H, Catapano L, Upregulation of lectin-like oxidized lowdensity lipoprotein receptor 1 (LOX-1) expression in human endothelial cells by modified high density lipoproteins. Biochem Biophys Res Commun., 2012; 428(2): 230-233.

38. Pop C, Crişan GC, Loghin F, Mogoşan CI, Advances in the detection and quantification of candidate and established biomarkers in heart failure. Rev Romana Med Lab, 2013; 21(3): 255-265.

39. Ramji DP, Davies TS. Cytokines in atherosclerosis: Key players in all stages of disease and promising therapeutic targets. Cytokine Growth Factor Rev., 2015; 26: 673-685.

40. Ridley AJ, Schwartz MA, Burridge K, Firtel RA, Ginsberg $\mathrm{MH}$, Cell migration: Integrating signals from front to back. Science, 2003; 302: 1704-1709.

41. Salmon M, Gomez D, Greene E, Shankman L, Owens GK, Cooperative binding of KLF4, pELK-1, and $\mathrm{HDAC} 2$ to a $\mathrm{G} / \mathrm{C}$ repressor element in the SM22 $\alpha$ promoter mediates transcriptional silencing during SMC phenotypic switching in vivo. Circ Res., 2012; 111: 685-696.

42. Sartipy P, Camejo G, Svensson L, Camejo EH, Phospholipase A(2) modification of low-density lipoproteins forms small high density particles with increased affinity for proteoglycans and glycosaminoglycans. J Biol Chem., 1999; 274: 25913-25920.

43. Schmitz B, Vischer P, Brand E, Schmidt-Petersen K, Korb-Pap A, Guske K, Increased monocyte adhesion by endothelial expression of VCAM-1 missense variation in vitro. Atherosclerosis., 2013; 230: 185-190.

44. Schulte D, Kuppers V, Dartsch N, Broermann A, Li $\mathrm{H}$, Stabilizing the VEcadherin- catenin complex blocks leukocyte extravasation and vascular permeability. EMBO J., 2011; 30(20): 4157-4170.

45. Shaw A, Xu Q, Biomechanical stress-induced signaling in smooth muscle cells: an update. Curr Vasc Pharmacol., 2003; 1: 41-58.

46. Su B, Mitra S, Gregg H, Flavahan S, Chotani MA, Redox regulation of vascular smooth muscle cell differentiation. Circ Res., 2001; 89: 39-46.

47. Townsend N, Wilson L, Bhatnagar P, Wickramasinghe K, Rayner M, Nichols M, Cardiovascular disease in Europe: epidemiological update 2016. Eur Hear J., 2016; 37(42): 3232-3245.

48. Upritchard JE, Oxidation of heparin treated lowdensity lipoprotein by peroxidases. Atherosclerosis, 1999; 146: 211-219.

49. Van Berkel TJ, Van Eck M HN, Al E, Scavenger receptor classes $\mathrm{A}$ and $\mathrm{B}$. Their roles in atherogenesis and the metabolism of modified LDL and HDL. Ann N Y Acad Sci., 2000; 902: 113-127.

50. Wang G, Jacquet L, Karamariti E, Xu Q, Origin and differentiation of vascular smooth muscle cells. J Physiol., 2015; 14: 3013-3030.

51. Wilkins E, Wilson L, Wickramasinghe K, Bhatnagar P, Leal J, Luengo-Fernandez R, EHN. Brussels; 2017.

52. Wong B, Meredith A, Lin D, McManus B, The biological role of inflammation in atherosclerosis. Can J Cardiol., 2012; 28: 631-641.

53. Wu MY, Li CJ, Hou MF, Chu PY, New insights into the role of inflammation in the pathogenesis of atherosclerosis. Mol Sci., 2017; 18: 1-18.

54. Xu S, Ogura S, Chen J, Little PJ, Moss J, Liu P, LOX- 1 in atherosclerosis: biological functions and pharmacological modifiers. Cell Mol Life Sci., 2013; 70: 2859-2872.

55. Zhao W, Wu C, Chen X, Cryptotanshinone inhibits oxidized LDL-induced adhesion molecule expression via ROS dependent NF-B pathways. Cell Adh Migr., 2015; 10: 1-11. 